\title{
USIA DAN POSISI KERJA PENGRAJIN PAYET BERPENGARUH TERHADAP KELUHAN LOW BACK PAIN
}

\author{
Izmaul Husna, Arifin, Gunung Setiadi \\ Poltekkes Kemenkes Banjarmasin Jurusan Kesehatan Lingkungan \\ Jl. Mistar Cokrokusumo No. 1A Banjarbaru Kalimantan Selatan 70714 \\ e-mail : izmaulhusnaaj11@gmail.com
}

\begin{abstract}
Age and Work Position of Sequin Craftsman affect Complaints of Low Back Pain. Low Back Pain (LBP) is one of the musculoskeletal disorders, psychological disorders and the result of wrong mobilization. $L B P$ is one of the most common health problems in the industrial community, one of which is Payet Craftsmen. The purpose of this study was to determine the relationship between age and work position with LBP complaints on Halidah Sequin Craftsmen in Cempaka Sub-District. Analytical research design with approach cross sectional. The sample in this study were workers who met the inclusion criteria amounting to 25 people. Data analysis used chi-square test. Test results of research was the age variable is sig value 0.122 (> 0.05). meaning that there is no relationship between age variable with LBP complaints on Halidah Sequin Craftsmen in Cempaka Sub-District. While test results of research were the variable work position is a sig value of 0.022 (<0.05). meaning that there is a relationship between work position variable and LBP complaints on Halidah Sequin Craftsmen in Cempaka Sub-District, with an Odds Ratio of 8,000 means that respondents who have high risk work positions are 8 more risk to complain of LBP compared to respondents who have moderate risk work positions.
\end{abstract}

Keywords: The age; Work Position; Complaints of Low Back Pain

\begin{abstract}
Abstrak: Usia Dan Posisi Kerja Pengrajin Payet Berpengaruh Terhadap Keluhan Low Back Pain. Low Back Pain (LBP) termasuk salah satu dari gangguan musculoskeletal, gangguan psikologis dan akibat dari mobilisasi yang salah. LBP merupakan salah satu masalah kesehatan yang umum terjadi di masyarakat industri, salah satunya pada Pengrajin Payet. Tujuan penelitian ini untuk Mengetahui hubungan umur dan posisi kerja dengan keluhan LBP pada Pengrajin Payet Halidah di Kecamatan Cempaka. Penelitian analitik dengan metode cross sectional. Sampel pada penelitian ini adalah pekerja yang memenuhi kriteria inklusi yang berjumlah 25 orang. Analisa data menggunakan uji chi square. Hasil uji penelitian pada variabel umur yaitu nilai sig 0,180 (>0.05). artinya tidak ada hubungan antara variabel umur dengan keluhan LBP pada pengrajin payet halidah di kecamatan cempaka. Sedangkan hasil uji penekitan pada variabel posisi kerja yaitu nilai sig 0,041 (< 0.05). artinya ada hubungan antara variabel posisi kerja dengan keluhan LBP pada pengrajin payet Halidah di Kecamatan Cempaka, dengan nilai Odds Ratio sebesar 8,000 berarti bahwa responden yang memiliki posisi kerja risiko tinggi 8 kali lebih berisiko untuk mengeluh LBP dibandingkan dengan responden yamg memiliki posisi kerja risiko sedang.
\end{abstract}

Kata Kunci: Umur; Posisi Kerja; Keluhan Low Back Pain

\section{PENDAHULUAN}

Pada zaman sekarang perlu adanya penerapan keselamatan dan kesehatan kerja di tempat kerja agar menjaga kelancaran proses kerja melalui upaya mengurangi faktor risiko kerja ${ }^{[1]}$. Menjamin keselamatan dan kesehatan untuk tenaga kerja di tempat kerja dengan mencegah terjadinya kecelakaan kerja dan penyakit akibat kerja merupakan definisi keselamatan dan kesehatan kerja.

Berdasarkan Permenaker nomor 5 tahun 2018, pada pasal 23 tentang Pengukuran dan pengendalian faktor ergonomi di tempat kerja yang memiliki potensi bahaya faktor ergonomi. Karena 
dengan desain kondisi kerja dan pengaturan cara kerja memiliki dampak pada kesehatan pekerja.

Organisasi Perburuhan Internasional (ILO) memperkirakan 2,78 juta pekerja meninggal setiap tahun karena kecelakaan kerja dan penyakit akibat kerja 86\% kematian dari perkiraan tersebut diakibatkan penyakit akibat kerja[2].

Menurut data Riskesdas tahun 2013, dapat diketahiu prevalensi penyakit musculoskeletal yang terjadi sebesar $11,9 \%$ berdasarkan diagnosa tenaga kesehatan dan sebesar 24,7\% berdasarkan gejala. Kalimantan selatan masuk dalam 11 provinsi yang memiliki prevalensi penyakit sendi di atas persentase nasional[3].

Salah satu dari gangguan musculoskeletal adalah Low Back Pain (LBP), yang merupakan gangguan psikologis dan akibat dari mobilisasi yang salah. LBP dapat terjadi dikerenakan bertambahnya umur yang mana pada kondisi ini dapat tejadi berkurangnya melakukan pergerakan baik ringan maupun berat. sehingga akan melemahkan fungsi otot-otot yang mendukung tulang belakang pada punggung dan perut [4]. LBP dapat terjadi juga karena postur tubuh yang salah, baik dalam keadaan duduk maupun berdiri, saat mengangkat beban dan lain-lain[5].

Kerajinan sulam payet merupakan kerajinan dengan benang dan jarum sebagai alat untuk menghias bahan menggunakan payet untuk memperindah dan mempercantik suatu desain. Bentukbentuk payet yaitu bentuk piringan, bentuk batangan dan bentuk pasiran. Tusuk yang digunakan dalam kerajinan sulam payet yaitu tusuk jelujur, tikam jejak, dan kombinasi antara keduanya[6].

\section{BAHAN DAN CARA PENELITIAN}

Jenis Penelitian yang dilakukan adalah jenis analitik yaitu menghubungkan umur dan posisi kerja dengan keluhan LBP pada pengrajin payet Halidah. Penelitian ini menggunakan cross sectional (potong silang) sebagai rancangan bangun, dan populasinya adalah seluruh pekerja pada Pengrajin Payet Halidah yang berjumlah 41 responden, dengan kriteria inklusi memiliki IMT normal, jenis kelamin perempuan, masa kerja lebih dari 3 tahun, tidak memiliki riwayat penyakit terkait trauma dan riwayat rangka. Sehingga populasi baru yang didapat baru berjumlah 25 responden.

Pengambilan sampel dilakukan menggunakan metode total sampling. Sehingga sampel berjumlah 25 responden. Penelitian ini menggunakan wawancara dan observasi untuk pengumpulan data. Wawancara berisi umur dan keluhan LBP menggunakan kuesioner Modifed Obswestry LBP Disability. Observasi berisi pengamatan posisi kerja menggunakan lembar observasi dengan metode Rapid Entry Body Assesment (REBA).

Pengolahan data yang dilakukan ialah editing yaitu melakukan pengecekan kelengkapan data, coding yaitu memberikan suatu symbol atau kode agar menjadi mudah saat menginput data, tabulating yaitu menggunakan tabel, dan entry data yaitu memasukkan data.

Pengolahan data yang digunakan menggunakan program komputer yaitu dengan analisis univariat dan analisis bivariat. Analisis Univariat dilakukan terhadap masing-masing variabel yaitu pada variabel bebas (umur dan posisi kerja) dan variable terikat (keluhan LBP). Sedangkan untuk mengetahui hubungan antara variabel bebas (umur dan posisi kerja) dengan variabel terikat (keluhan LBP), menggunakan uji chi square sebagai Analisis bivariat.

\section{HASIL PENELITIAN DAN PEMBAHASAN}

Dari pengumpulan data yang dilakukan pada 25 pekerja, hasil yang didapat pada penelitian ini yaitu:

\section{Umur responden}

Hasil wawancara yang telah dilakukan diketahui bahwa pengrajin memiliki umur yang beragam. 
Tabel 1. Umur Responden

\begin{tabular}{ccccc}
\hline No. & & Umur & Jumlah (Orang) & Presentasi (\%) \\
\hline 1. & $<30$ tahun & & 6 & 24 \\
2. & $>30$ tahun & & 19 & 76 \\
& & Jumlah & 25 & 100 \\
\hline
\end{tabular}

Berdasarkan tabel 1 dapat diketahui dari 25 pekerja ada 6 (24\%) responden memiliki umur kurang dari 30 tahun, dan ada 19 (76\%) responden memiliki umur mulai dari 30 tahun hingga lebih dari 30 tahun.

\section{Posisi Kerja Responden}

Hasil observasi yang dilakukan menggunakan lembar observasi posisi kerja dengan metode REBA (Rapid Entire Body Assesement) kepada para pekerja.

Tabel 2. Posisi Kerja Responden

\begin{tabular}{cccc}
\hline No. & Posisi Kerja & Jumlah (orang) & Presentasi (\%) \\
\hline 1. & Risiko Rendah & 0 & 0 \\
2. & Risiko Sedang & 12 & 48 \\
3. & Risiko Tinggi & 13 & 52 \\
& Jumlah & 25 & 100 \\
\hline
\end{tabular}

Berdasarkan tabel 2 dapat diketahui dari 25 sempel responden didapatkan hasil yaitu sebanyak 12 (48\%) responden memiliki risiko sedang dan sebanyak 13 (52\%) responden memiliki risiko tinggi.

\section{Keluhan LBP pada Responden}

Hasil wawancara yang dilakukan menggunakan kuesioner pemeriksaan fungsional dengan menggunakan "Modified Oswestry Low Back Pain Disability Questionnaire" kepada para pekerja.

Tabel 3. Keluhan LBP pada Responden

\begin{tabular}{cccc}
\hline No. & Keluhan LBP & Jumlah (orang) & Presentasi (\%) \\
\hline 1. & Tidak Mengeluh & 15 & 60 \\
2. & Mengeluh & 10 & 40 \\
& Jumlah & 25 & 100 \\
\hline
\end{tabular}

Berdasarkan tabel 3 dapat diketahui dari 25 sempel responden didapatkan hasil yaitu sebanyak $15(60 \%)$ responden tidak mengeluh low back pain dan sebanyak $10(40 \%)$ responden mengeluh low back pain.

\section{Analisis Hubungan Umur dengan Keluhan LBP Responden}

Tabel 4. Analisis hubungan umur dengan keluhan LBP Responden

\begin{tabular}{|c|c|c|c|c|c|c|}
\hline \multicolumn{7}{|c|}{ Keluhan Low back Pain } \\
\hline \multicolumn{2}{|c|}{ Umur } & \multirow{2}{*}{$\begin{array}{l}\text { Tidak } \\
\text { Nyeri }\end{array}$} & Mengeluh Rasa & \multirow{2}{*}{$\begin{array}{l}\text { Mengeluh Rasa Nyeri } \\
1\end{array}$} & \multirow{2}{*}{$\begin{array}{l}\text { Total } \\
6\end{array}$} & Sig \\
\hline Kurang dari 30 tahun & Count & & & & & 0.180 \\
\hline & Expected Count & & 3.6 & 2.4 & 6.0 & \\
\hline & $\%$ within umur & & $83.3 \%$ & $16.7 \%$ & $100.0 \%$ & \\
\hline dari 30 hingga lebih 30 & Count & & 9 & 10 & 19 & \\
\hline tahun & Expected Count & & 10.6 & 8.4 & 19.0 & \\
\hline & $\%$ within umur & & $47.4 \%$ & $52.6 \%$ & $100.0 \%$ & \\
\hline Total & Count & & 15 & 10 & 25 & \\
\hline & Expected Count & & 15.0 & 10.0 & 25.0 & \\
\hline & $\%$ within umur & & $60.0 \%$ & $40.0 \%$ & $100.0 \%$ & \\
\hline
\end{tabular}


Berdasarkan tabel 4 didapat hasil yaitu dari 15 responden yang tidak mengeluh LBP ada $5(83,3 \%)$ responden yang memiliki umur kurang dari 30 tahun dan ada $9 \quad(47,4 \%)$ responden yang memiliki umur dari 30 hingga lebih 30 tahun, sedangkan dari 10 responden yang mengeluh LBP ada $1(16,7 \%)$ responden yang memiliki umur kurang dari 30 tahun dan ada $10(52,6 \%)$ responden yang me- miliki umur dari 30 hingga lebih 30 tahun.

Hasil analisis dengan uji chi square didapatkan nilai sig 0,180 (lebih besar dari 0,05). Hal ini dapat diartikan bahwa tidak ada hubungan antara 4ariable umur dengan keluhan LBP pada pengrajin payet Halidah di Kecamatan Cempaka.

\section{Analisis Hubungan Posisi Kerja dengan Keluhan LBP Responden}

Tabel 5. Analisis Hubungan Posisi Kerja dengan Keluhan LBP Responden

\begin{tabular}{|c|c|c|c|c|c|c|}
\hline \multicolumn{7}{|c|}{ Keluhan Low back Pain } \\
\hline & hur & $\begin{array}{l}\text { Tidak Mengeluh } \\
\text { Rasa Nyeri }\end{array}$ & Mengeluh Rasa Nyeri & Total & Sig & Odd Ratio \\
\hline \multirow[t]{3}{*}{ Risiko sedang } & Count & 10 & 2 & 12 & 0.041 & 8.000 \\
\hline & Expected Count & 7.2 & 4.8 & 12.0 & & \\
\hline & $\%$ within umur & $83.3 \%$ & $16.7 \%$ & $100.0 \%$ & & \\
\hline \multirow[t]{3}{*}{ Risiko tinggi } & Count & 5 & 8 & 13 & & \\
\hline & Expected Count & 7.8 & 5.2 & 13.0 & & \\
\hline & $\%$ within umur & $38.5 \%$ & $61.5 \%$ & $100.0 \%$ & & \\
\hline \multirow[t]{3}{*}{ Total } & Count & 15 & 10 & 25 & & \\
\hline & Expected Count & 15.0 & 10.0 & 25.0 & & \\
\hline & $\%$ within umur & $60.0 \%$ & $40.0 \%$ & $100.0 \%$ & & \\
\hline
\end{tabular}

Berdasarkan tabel 5 didapat hasil yaitu dari 15 responden yang tidak mengeluh LBP ada $10(83,3 \%)$ responden yang memiliki umur kurang dari 30 tahun dan ada $5 \quad(38,5 \%)$ responden yang memiliki umur dari 30 hingga lebih 30 tahun, sedangkan dari 10 responden yang mengeluh LBP ada $2(16,7 \%)$ responden yang memiliki umur kurang dari 30 tahun dan ada 8 (61,5\%) responden yang memiliki umur dari 30 hingga lebih 30 tahun.

Hasil analisis dengan uji chi square didapatkan nilai sig 0,041 (lebih kecil dari 0,05). Hal ini dapat diartikan bahwa ada hubungan antara variabel posisi kerja dengan keluhan LBP pada pengrajin payet halidah di kecamatan cempaka. Dengan nilai odds ratio sebesar 8,000 berarti bahwa responden yang memiliki posisi kerja risiko tinggi 8 kali lebih berisiko untuk mengeluh LBP dibandingkan dengan responden yamg memiliki posisi kerja risiko sedang.

\section{Analisis Hubungan Umur dengan Keluhan LBP Responden}

Berdasarkan tabel 4 Setelah dilakukan uji statistik menggunakan uji Chi Square dari 25 responden dapat diketahui bahwa "tidak ada hubungan antara variabel umur dengan keluhan LBP pada pengrajin payet Halidah di Kecamatan Cempaka". Hal ini dapat diartikan bahwa umur tidak berkorelasi dengan terjadinya keluhan LBP pada pengrajin payet Halidah di Kecamatan Cempaka. Hal ini terjadi karena kemungkinan LBP pada penelitian ini di pengaruhi oleh hal lain pada masingmasing responden seperti kebiasaan dan aktifitas sehari-hari selain dari memayet pakaian.

Berdasarkan hasil penelitian Wahab, 2006[7] yang dilakukan pada nelayan didapatkan nilai $\mathrm{p}$ value pada umur lebih dari 0,05 ( $\mathrm{p}=>0,05)$ yaitu 1,583 . Hal ini menunjukkan bahwa umur tidak berhubungan dengan trerjadinya nyeri punggung bawah (low back pain) pada nelayan.

Berdasarkan hasil penelitian Deli Sulvici Sitepu, Muhammad Makmur Sinaga, 2015(8) didapatkan hasil uji chi square yang > 0.05. yang menunjukkan bahwa variabel faktor individu umur tidak berhubungan dengan keluhan LBP. Umur tidak berhubungan dengan keluhan LBP dikarenakan dari muda petani jeruk sudah merasakan LBP, hal tersebut mengakibatkan petani jeruk sudah terbiasa dengan rasa sakit di bagian punggung bawah. 


\section{Analisis Hubungan Posisi Kerja dengan Keluhan LBP Responden}

Berdasarkan tabel 5 Setelah dilakukan uji statistik menggunakan uji Chi Square dari 25 responden dapat diketahui bahwa "ada hubungan antara variabel posisi kerja dengan keluhan LBP pada pengrajin payet Halidah di Kecamatan Cempaka". Hal ini dapat diartikan bahwa posisi kerja berkorelasi dengan terjadinya keluhan LBP pada pengrajin payet Halidah di Kecamatan Cempaka. Dan risk hubungan posisi kerja dengan keluhan LBP pengrajin payet Halidah di Kecamatan Cempaka di dapat hasil bahwa responden yang memiliki posisi kerja risiko tinggi 8 kali lebih berisiko untuk mengeluh LBP dibandingkan dengan responden yamg memiliki posisi kerja risiko sedang.

Berdasarkan obeservasi yang dilakukan terhadap responden dapat diketahui bahwa posisi melakukan pekerjaan memayet ini banyak diantaranya melakukan posisi kerja yang kurang baik misalnya duduk tanpa sandaran, duduk bekerja pada waktu yang cukup lama, tangan mangangkat dan menurun secara berulang-ulang seperti saat menarik dan menusuk benang, posisi kerja membungkukkan punggung dan agak condong ke depan.

Berdasarkan hasil penelitian Widjaya, 2012(9) didapat nilai $\mathrm{P}=0,00$, hal ini menunjukkan bahwa ada hubungan antara sikap dan posisi kerja dengan kejadian LBP, yaitu 1,3 kali lebih beresiko terjadinya LBP pada pekerja postur janggal. Berdasarkan hasil penelitian Umami, 2014 (4) didapat hasil $\mathrm{p}=0,001$ dengan menggunakan uji cramer coefficient c menunjukkan ada hubungan yang signifikan antara sikap kerja duduk dengan keluhan LBP, hal ini berarti bahwa paling banyak mengalami keluhan LBP adalah pekerja dengan sikap kerja duduk tidak ergonomis.

\section{KESIMPULAN DAN SARAN}

Hasil uji yang didapatkan menunjukkan bahwa tidak ada hubungan antara umur dengan keluhan LBP pada pengrajin payet, Hasil uji yang didapatkan menunjukkan bahwa ada hubungan antara posisi kerja dengan keluhan LBP pada pengrajin payet.

Bagi Pengusaha dan Pengrajin Payet diharapkan agar dapat memperbaiki penyebab terjadinya keluhan dan dapat menerapkan saran dari pemecahan masalah yang telah diberikan, bagi Instansi Terkait diharapkan dapat menerima saran dan masukan mengenai pentingnya pengendalian faktor ergonomi dalam rangka upaya pembinaan dan mengurangi risiko terjadinya penyakit akibat kerja salah satunya adalah Low Back Pain, dan bagi Peneliti Selanjutnya diharapkan dapat meneliti pada variabel lainnya seperti umur, beban kerja, lama kerja dan repetisi.

\section{DAFTAR PUSTAKA}

1. Budiono, A.M.S. RMSJ dan AP. Hiperkes dan Keselamatan Kerja. Edisi Kedua. Semarang: Badan Penerbit Universitas Diponegoro; 2009.

2. ILO. Meningkatkan Keselamatan dan Kesehatan Pekerja Muda [Internet]. Kantor Perburuhan Internasional , CH1211 Geneva 22, Switzerland. 2018. 23 p. Available from: http://www.oit.org/wcmsp5/groups/ public/---asia/---ro-bangkok/---ilojakarta/documents/publication/wcms _627174.pdf

3. Santosa, A., I Putu E.W. \& Purwata T. Korelasi Lama Duduk dengan Nyeri Punggung Bawah pada Pekerja Hotel The Grand Santhi Denpasar. E-Jurnal Med. 2016;5(10): 1-5.

4. Umami D. Hubungan antara Karakteristik Responden dan Sikap Kerja Duduk dengan Keluhan Nyeri Punggung Bawah (Low Back Pain) Pada Pekerja Batik Tulis. Pustaka Kesehat [Internet]. 2014;2(1):72-8. Available from: http://jurnal.unej.ac.id/index.php/JPK /article/view/599

5. Sulaeman YA, Kunaefi TD. Low Back Pain (LBP) pada Pekerja di Divisi Minuman Tradisional (Studi Kasus CV. Cihanjuang Inti Teknik). J Teh Lingkung. 2015;21(2):201-11.

6. Fallis A. Pemberdayaan Ekonomi 
Pekerjaan Rumah Tangga Melalui Pelatihan Kerajinan Payet Dikelulrahan Sumurbroto Kecamatan Banyumanik Semarang. J Chem Inf Model. 2013;53(9):1689-99.

7. Wahab A. Faktor-Faktor Yang Berhubungan Dengan Keluhan Nyeri Punggung Bawah (Low Back Pain) Pada Nelayan Di Desa Batu Karas Kecamatan Cijulang Pangandaran. 2006;11(1):35-40.
8. Deli Sulvici Sitepu, Muhammad Makmur Sinaga HS lubi. Faktor-Faktor Yang Berhubungan Dengan Keluhan Low Back Pain Pada Petani Jeruk Di Desa Dokan Kecamatan Merek Kabupaten Karo. 2015;

9. Widjaya. Faktor-faktor yang Berhubungan dengan Kejadian Low Back Pain pada Pekerja Furniture. 2012;85-90. 